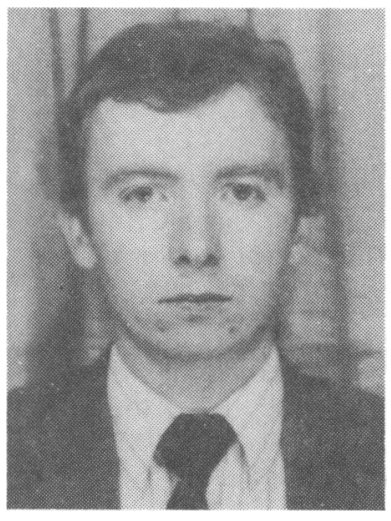

M. McDermott

\section{OSTEOARTHROSIS IN RUNNERS WITH KNEE PAIN}

\author{
M. MCDERMOTT, MRCPI* and P. FREYNE, FRCR** \\ * Research Assistant, St. James's Hospital, Dublin \\ * * Consultant Radiologist, St. James's Hospital, Dublin
}

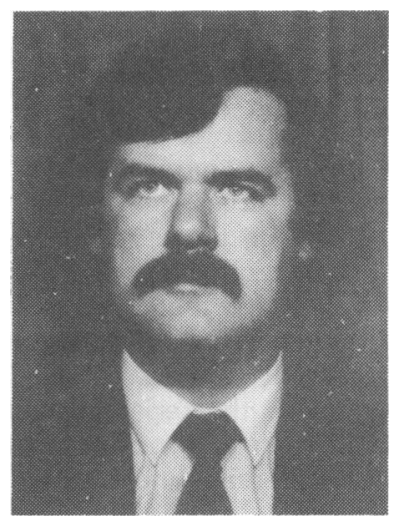

P. Freyne

\title{
ABSTRACT
}

A clinical and radiological study of the knee joints of twenty middle and long distance runners, complaining of knee pain, was carried out. Osteoarthrosis of varying degree was found in six of the runners. A torn meniscus requiring surgery was found in one athlete, and another had considerable ligamentous laxity - both of these conditions predispose to the development of degenerative changes. Degenerative changes were significantly associated with the presence of genu varum $(p<0.01)$ and history of severe injury $(p<0.05)$. The number of years spent training was significantly greater in the affected group than in the unaffected group $(p<0.05)$.

Key Words: Running, Osteoarthrosis, Injury, Genu varum.

\section{INTRODUCTION}

The pattern of joint degeneration varies in the different categories of sport and is related to the particular joints being overstressed. Thus osteoarthrosis of the elbow has been reported in tennis players (Priest et al, 1977), the cervical spine in footballers (Sortland et al, 1982) and the patella in cyclists (Bagneres, 1967). These findings support the hypothesis that repetitive high stress due to impulsive loading is a mechanism of joint degeneration (Radin et al, 1972). However, a study of the hip joints of former Finnish champion distance runners revealed a reduced incidence of osteoarthrosis compared with the non-running population (Puranen et al, 1975), and likewise an absence of degenerative changes in the upper limb joints of competitive weight lifters has been reported (Fitzgerald and McLatchie, 1980). It is possible that some protective factors operate to prevent joint failure in these activities. An increase in joint mobility (Harrison et al, 1953), and improved

\footnotetext{
"Present address:
}

Service de Rhumatologie, Hopital des Charpennes,

27 Grande rue des Charpennes, 69603 Villeurbanne,

Cedex,

France cartilage nutrition (Radin and Paul, 1972) have both been postulated as protective mechanisms.

The purpose of this study was to discover the factors likely to influence the development of osteoarthrosis of the knee among runners. We selected a group of experienced middle and long distance runners all suffering from knee pain as the most likely subjects to have osteoarthrosis. We then compared the group having osteoarthrosis with the group free of degenerative changes but having knee pain.

\section{MATERIALS AND METHODS}

\section{Subjects and Procedures}

Twenty male middle and long distance runners who had been competing for at least five years were selected randomly for the study from a group complaining of knee pain. All subjects were suffering from knee pain for at least three months duration at the time of the study.

Each athlete was asked to complete a questionnaire with details of his age, number of years of training and competition and his average weekly training mileage in the previous five years in so far as he had recorded it. Each subject was also required to give a detailed account of injuries to his knees with particular emphasis on 
bony, ligamentous and cartilagenous damage; for example he was asked about the occurrence of locking, effusion (swelling), dislocation, fracture and whatever investigations and diagnosis, if any, were made at the time.

Each participant was examined clinically and radiologically. The knees were carefully examined for ligamentous, patellar or meniscal pathology and arthroscopy was performed where considered necessary. Signs of osteoarthrosis were sought, and skeletal malformations predisposing to joint degeneration e.g. genu varum and valgum were sought. An intercondylar distance of greater than $2 \mathrm{~cm}$ with the medial malleoli in apposition was considered to constitute significant genu varum. Genu valgum was diagnosed where intermalleolar distance exceeded $2 \mathrm{~cm}$.

\section{Radiological Examination}

Single weight bearing views in the antero-posterior plane, with lateral and skyline views of both knee joints, were carried out. The radiological changes considered as evidence of osteoarthrosis were joint space narrowing, sub-chondral sclerosis, bony cysts, osteophytes and periarticular ossicles (Fairbank, 1948). Spiking of the tibial spines per se was not considered diagnostic of osteoarthrosis.

Statistical comparison between the two groups was done for age, training mileage and years spent running, using Student's t-test for uncorrelated samples. Chisquared analysis was used to compare the incidence of certain features in the two groups. A P value of less than 0.05 was taken to indicate a significant result.

\section{RESULTS}

There were six subjects found to have degenerative changes radiologically. Of these subjects, five had clinical findings suggestive of osteoarthrosis, and all six had significant genu varum (Table I). There was a history of trauma in four of these six subjects, while three of the fourteen unaffected athletes had experienced acute injury.

Chi-squared analysis established that a significant association existed between degenerative changes and both the presence of genu varum ( $p<0.01$ ) and the history of knee injury $(p<0.05)$. The athletes with degenerative knee changes had considerably greater incidence of genu varum, had experienced more knee

\section{TABLE I}

Clinical and radiological features of the group with degenerative changes $(n=6)$

\begin{tabular}{|c|c|c|c|c|c|}
\hline Subject & Age & Miles/Week & Years Running & & History of Trauma \\
\hline 1 & 44 & 65 & 24 & i) & $\begin{array}{l}\text { Direct trauma to right } \\
\text { patella at } 34 \text { years. }\end{array}$ \\
\hline \multirow{3}{*}{2} & \multirow{3}{*}{33} & \multirow{3}{*}{6} & \multirow{3}{*}{8} & ii) & $\begin{array}{l}\text { Pain and swelling for } \\
3 \text { weeks. }\end{array}$ \\
\hline & & & & i) & $\begin{array}{l}\text { Twisted right knee at } \\
18 \text { years }\end{array}$ \\
\hline & & & & ii) & $\begin{array}{l}\text { Unable to weight-bear } \\
\text { for } 2 \text { weeks. }\end{array}$ \\
\hline
\end{tabular}

$29 \quad 100$

4

55

50

28

None

None

i) Bakers cyst left knee

ii) Genu varum

i) Local tenderness at origin of Infra-Patellar ligament;

ii) Genu varum.

i) Negative;

ii) Genu varum.

i) Bilateral knee crepitus;

ii) Genu varum.

i) Decreased flexion right knee;

ii) patello-femoral crepitus;

iii) Genu varum

i) Poor quadriceps development bilateraily;

ii) Painful right patellar compression;

iii) Genu varum
Radiological Changes

i) Malalignment of old fracture right patella,

ii) patellar osteophytes.

i) Narrowing of medial compartment right knee

i) Narrowing medial compartment left knee,

ii) Spiking tibial spines.

i) Narrowing medial compartment both knees,

ii) Calcification of InfraPatellar ligaments.

i) Marked narrowing lateral compartment right knee,

ii) patellar and femorotibial osteophytes.

i) Femoro-tibial osteophytes and narrowed joint space both knees.

ii) Patellar osteophytes right knee. 
injuries and had been running for a significantly greater number of years $(p<0.05)$. There was no significant difference in the weekly mileage or age between the two groups (Table II).

\section{TABLE II}

Age, training and running experience of affected and unaffected groups (mean \pm SD)

$\begin{array}{lccc} & \begin{array}{c}\text { Affected } \\ \text { Group }\end{array} & \begin{array}{c}\text { Unaffected } \\ \text { Group }\end{array} & \text { P Value } \\ \text { Age } & 38.5 \pm 9.5 & 32.9 \pm 5.0 & \text { NS } \\ \text { Miles/Week } & 61.8 \pm 33.2 & 41.2 \pm 18.0 & \text { NS } \\ \text { Years of Running } & 19.6 \pm 7.8 & 11.9 \pm 4.6 & <0.05\end{array}$

Of the three subjects without radiological changes who had experienced significant trauma, one was diagnosed at arthroscopy as having a torn medial meniscus requiring meniscectomy; another had considerable lateral collateral knee ligament laxity and the third had minor elongation of the lateral collateral ligament. Overall, of the seven athletes who had experienced trauma to the knee, three had experienced the injury playing football, two had accidents at work, and two were injured while training or racing.

A radiological diagnosis of chrondromalacia patellae was not made on any of the subjects, although several in both groups had symptoms and signs suggestive of this diagnosis. The subjects with patello-femoral degeneration however, may represent an advanced stage of this condition which had progressed to osteoarthrosis.

\section{DISCUSSION}

This study found a relatively high incidence of degenerative changes in runners complaining of knee pain $(30 \%)$. However, the high incidence of trauma and genu varum in the affected group, both of which are recognised as predisposing factors to osteoarthrosis (Ory, 1964), suggests that running per se was not necessarily the main aetiological factor. Rall et al (1964) have reported an incidence of $\mathbf{8 3 . 4 \%}$ of osteoarthrosis among American football players who had sustained knee injury. Association football as a leading cause of sports injuries has been previously reported (Axelsson et al, 1980). It is also possible that the athletes with most severe symptoms are more likely to participate in a study of this nature and to seek a diagnosis for their symptoms (Adams, 1976).
Due to the small number of athletes in the affected group and to several interplaying factors, it is difficult to distinguish between the role of trauma and genu varum in causing osteoarthrosis. Only subjects three and four failed to report significant trauma and on close questioning both athletes revealed a history of active participation in contact sports which may have produced a background of less severe trauma going unnoticed.

Subject five in the affected group is an example of several possible factors at work in causing his joint degeneration. He presented with a history of trauma to his right knee and was one of the most experienced and hardest training runners. His left knee was entirely free of radiological change whilst his right, in the aftermath of meniscectomy eleven years previously, showed severe degenerative changes. This would suggest that in this case trauma along with the ensuing meniscectomy was the overriding factor and the presence of genu varum was not causal.

Both ligamentous laxity (Kirk et al, 1967) and meniscectomy (Jackson, 1968) have been described as predisposing to osteoarthrosis. Two of the three subjects with clear X-rays, having had injuries, are therefore at risk of developing joint changes in the future. The role of trauma in causing osteoarthrosis is once more underlined in this study.

All subjects continued to train and compete at the time of the study. It is interesting to speculate whether this activity will accelerate or slow up the degenerative process already present in the affected group. Further studies are required to shed light on this important problem.

All subjects were advised regarding footwear, training mileage and the type of surface best suited to reducing the load on the injured joint. However only subjects two and six agreed to a reduction in training - in both subjects pain limited their training mileage.

Treatment in the affected group consisted of physiotherapy, with stretching and quadriceps exercises where indicated. Subjects were not prescribed analgesics in the first instance as it was felt that they might mask the symptoms and cause them to aggravate their condition.

The effects of heavy training on osteoarthrosis of the knee has not been well studied. However due to the reluctance of these athletes to forego training and racing while suffering from this condition there is a large supply of subjects for further studies.

\section{REFERENCES}

Adams, I. D., 1976 "Osteoarthrosis and sport". Clinics in Rheumatic Diseases 2: 523-542. 
Axelsson, R., Renstrøm, P. and Swensson, H. O., 1980 "Akuta irottsskador pa ett centrallasarett". Läkartidningen 41: 3615-3617.

Bagneres, M., 1967 "Lésions ostéo-articulaires chroniques des sportifs". Rheumatologie halnoelogia allergiologia 19: 41-50.

Fairbank, T. J., 1948 "Knee joint changes after meniscectomy". Journal of Bone and Joint Surgery 30B: 664-670.

Fitzgerald, B. and McLatchie, G. R., 1980 "Degenerative joint disease in weight lifters, fact or fiction?" British Journal of Sports Medicine 13: 97-101.

Harrison, M. H. M., Schajowics, F. and Trueta, J., 1953 "Osteoarthritis of the hip. A study of the nature and evolution of the disease". Journal of Bone and Joint Surgery 35B: 59.

Jackson, J. P., 1968 "Degenerative changes in the knee after meniscectomy". British Medical Journal ii: 525-527.

Kirk, J. A., Ansell, B. M. and Bywater, E. G. L., 1967 "The hypermobility syndrome". Annals of the Rheumatic Diseases 26: 419-425.

Ory, M., 1964 “Des influences mécaniques dans l'apparition et le développement des manifestations dégénératives du genou". Journal Belge du Rhumatologie et de Medecine Physique 28: 74-85.

Priest, J. P., Jones, M. M., Tichener, C. J. C. and Nagel, O. A., 1977 "Arm and elbow changes in expert tennis players". Minnesota Medicine 60: 399-404.

Puranen, J., Ala-Ketola, L., Peltokallio, P. and Searela, J., 1975 "Running and primary osteoarthritis of the hip". British Medical Journal ii: 424.

Radin, E. L. and Paul, I. L., 1972 "A consolidated concept of joint lubrication". Journal of Bone and Joint Surgery 54A: 607-617.

Radin, E. L., Paul, I. L. and Rose, R. M., 1972 "Role of mechanical factors in pathogenesis of primary osteoarthritis". Lancet v: 519-522.

Rall, K. L., McElroy, G. L. and Keats, T. E., 1964 "A study of long term effects of football injury to the knee". Missouri Medicine 61: 435-438.

Sortland, O., Tysvaer, A. T. and Storli, O. V., 1982 "Changes in the cervical spine in Association Football players". British Journal of Sports Medicine 16: 80-82. 